OPEN ACCESS

Edited by: Kian Fan Chung,

Imperial College London, United Kingdom

Reviewed by: Garry M. Walsh,

University of Aberdeen, United Kingdom

Leo Koenderman, Utrecht University, Netherlands

*Correspondence:

Mats W. Johansson mwjohansson@wisc.edu

Specialty section:

This article was submitted to Pulmonary Medicine,

a section of the journal

Frontiers in Medicine

Received: 23 March 2017 Accepted: 26 May 2017 Published: 12 June 2017

Citation:

Johansson MW (2017) Eosinophil

Activation Status in Separate

Compartments and Association with Asthma.

Front. Med. 4:75.

doi: 10.3389/fmed.2017.00075

\section{Eosinophil Activation Status in Separate Compartments and Association with Asthma}

\author{
Mats W. Johansson* \\ Department of Biomolecular Chemistry, University of Wisconsin, Madison, WI, United States
}

Asthma is frequently characterized by eosinophil-rich airway inflammation. Airway eosinophilia is associated with asthma exacerbations and likely plays a part in airway remodeling. Eosinophil recruitment from the bloodstream depends on circulating eosinophils becoming activated, which leads to eosinophil arrest on activated endothelium, extravasation, and continued movement through the bronchial tissue by interaction with the extracellular matrix (ECM). Circulating eosinophils can exist at different activation levels, which include non-activated or pre-activated (sensitized or "primed"). Further, the bloodstream may lack pre-activated cells, due to such eosinophils having arrested on endothelium or extravasated into tissue. Increased expression, and in some instances, decreased expression of cell-surface proteins, including CD44, CD45, CD45R0, CD48, CD137, neuropeptide S receptor, cytokine receptors, FC receptors, and integrins (receptors mediating cell adhesion and migration by interacting with ligands on other cells or in the ECM), and activated states of integrins or Fc receptors on blood eosinophils have been reported to correlate with aspects of asthma. A subset of these proteins has been reported to respond to intervention, e.g., with anti-interleukin (IL)-5. How these surface proteins and the activation state of the eosinophil respond to other interventions, e.g., with anti-IL-4 receptor alpha or anti-IL-13, is unknown. Eosinophil surface proteins suggested to be biomarkers of activation, particularly integrins, and reports on correlations between eosinophil activation and aspects of asthma are described in this review. Intermediate activation of beta1 and beta2 integrins on circulating eosinophils correlates with decreased pulmonary function, airway inflammation, or airway lumen eosinophils in non-severe asthma. The correlation does not appear in severe asthma, likely due to a higher degree of extravasation of pre-activated eosinophils in more severe disease. Bronchoalveolar lavage (BAL) eosinophils have highly activated integrins and other changes in surface proteins compared to blood eosinophils. The activation state of eosinophils in lung tissue, although likely very important in asthma,

\footnotetext{
Abbreviations: ADAM, a disintegrin and metalloproteinase; BAL, bronchoalveolar lavage; $\beta c$, common $\beta$ chain (of IL-3, IL-5, and GM-CSF receptors); C, complement; CD, cluster of differentiation; ECM, extracellular matrix; Fc, fragment, crystallizable (of immunoglobulin); FENO, fraction of exhaled nitric oxide; $\mathrm{FEV}_{1}$, forced expiratory volume in $1 \mathrm{~s}$; FVC, forced vital capacity; GLP, glucagon-like peptide; GM-CSF, granulocyte macrophage-colony stimulating factor; HLA, human leukocyte antigen; ICAM, intercellular adhesion molecule; IGSF, immunoglobulin superfamily member; IL, interleukin; ILA, induced by lymphocyte activation; LAMP, lysosome-associated membrane protein; LPS, lipopolysaccharide; mAb, monoclonal antibody; $\mathrm{PC}_{20}$, provocative concentration of methacholine or histamine producing a $20 \%$ fall in $\mathrm{FEV}_{1}$; $\mathrm{PD}-\mathrm{L}$, programmed death ligand; PSGL, P-selectin glycoprotein ligand; R, receptor; ROC, receiver-operator characteristic; TNFRSF, tumor necrosis factor receptor superfamily member; VCAM, vascular cell adhesion molecule.
} 
is largely unknown. However, some recent articles, mainly on mice but partly on human cells, indicate that tissue eosinophils may have a surface phenotype(s) different from that of sputum or BAL eosinophils.

Keywords: eosinophils, activation, asthma, integrins, interleukin-5

\section{INTRODUCTION}

Asthma is often characterized by eosinophil-rich airway inflammation (1-8). Such eosinophilic inflammation is associated with exacerbations and appears to participate in airway remodeling $(1,8-14)$. Eosinophil recruitment from the bloodstream depends on circulating blood eosinophils becoming activated, which leads to eosinophil arrest on activated endothelium, extravasation, and continued movement through the bronchial tissue and lumen by interaction with the extracellular matrix (ECM) (2, 8, 15-17). Circulating eosinophils can exist in different states, including non-activated, or pre-activated or "primed" $(8,18)$. Moreover, the bloodstream may lack pre-activated cells, due to such eosinophils having extravasated (8). Increased expression, and in some instances, decreased expression of cell-surface proteins and activated states of integrins or Fc receptors on blood eosinophils have been reported to correlate with asthma $(8,19)$. Some of these proteins have been reported to respond to intervention (19).

This review will discuss eosinophil surface proteins proposed to be biomarkers of eosinophil activation and evidence for associations between the activation status of eosinophils and aspects of asthma. The search strategy is described in the notes for Table 1. Further, this review will discuss a subset of these proteins that appears to be downregulated or less activated on circulating eosinophils in severe asthma or after whole-lung antigen challenge. Finally, it will discuss how some eosinophil surface proteins respond to pharmaceutical intervention. A model of eosinophil activation status, focusing on integrins, in the circulation and the airway will also be presented.

\section{EOSINOPHIL SURFACE PROTEINS ALTERED AFTER ANTIGEN CHALLENGE, IN THE AIRWAY, OR IN ASTHMA}

Upregulation or downregulation of eosinophil surface proteins and activated conformations of integrins and Fc receptors have been proposed to be biomarkers of eosinophil activation, in many cases due to the reaction of eosinophils to various stimuli in vitro (2, 8, 17-19, 58-61). Many, but not all, i.e., not all that change in response to in vitro stimulation, of these surface proteins have been reported to be altered on blood eosinophils after wholelung or segmental lung antigen challenge, or on bronchoalveolar lavage (BAL), or sputum eosinophils (Table 1). In addition, the surface proteins may be altered on blood eosinophils in asthma or in a manner that correlates with features of asthma (Table 1) (19). Segmental and whole-lung antigen challenge are models of allergic airway inflammation (62) and asthma exacerbation (63), respectively. Up- or downregulation in Table 1 refers to changed or different protein expression of a cell surface protein, which usually has been determined by flow cytometry. Further, alterations are listed independently of what the mechanism may be, e.g., translocation to the surface from intracellular granules or the effect of increased transcription or protein synthesis and may consist of an alteration in mean or median expression on all eosinophils or an alteration in the percentage of expressing eosinophils $(8,19)$. Some references have studied purified cells, while others have used whole blood, BAL, or sputum cells. An unfractionated sample is beneficial in that just a small volume or number of cells is needed and that isolated cells in vitro may be different and more activated than cells in vivo $(8,19,64,65)$. Regarding more detailed information about individual proteins, please see Ref. (8).

Several proteins, including CD45, CD45R0, CD48, CD137, IL-17 receptor $(\mathrm{R}) \mathrm{A}$ and $\mathrm{B}, \alpha_{\mathrm{L}}$ integrin, and some of the $\mathrm{Fc}$ receptors, are increased or decreased on circulating eosinophils in asthma compared to normal, non-allergic healthy individuals (Table 1) $(8,19)$. One specific example is that IL-17R and B (subunits of IL-25R) are increased in patients with non-severe allergic asthma but not in non-asthmatic patients with atopy $(8,19,49)$. In the case of some proteins, reports are conflicting. For instance, some workers reported Fc $\gamma$ RIII (CD16) to be increased on blood eosinophils in allergic asthma (or allergic rhinitis) (46) (Table 1), while other authors reported no alterations in airway allergies when compared to control subjects $(8,19,66)$.

The expression level of a particular protein may not only be an effect of the eosinophil having been exposed to cytokines or other stimuli but may also partly result from actions of regulatory factors in vivo. One recent example of such a factor that may regulate eosinophil activation is glucagon-like peptide (GLP)-1, a member of the incretin family of hormones, which regulates glucose metabolism (47). A GLP-1 analog inhibited upregulation of $\alpha_{M}$ integrin and CD69 in vitro in response to lipopolysaccharide (47). Further, expression of GLP-1 receptor was lower on blood eosinophils in patients with allergic asthma than in normal controls (Table 1). The lower level of GLP-1R in asthma than in healthy subjects indicates that the eosinophil response to activating stimuli may be more regulated by GLP-1 in healthy persons and that eosinophil activation may be more easily achieved in asthma than in health. Further, Mitchell and colleagues suggest that GLP-1 agonists may have additional indications in treating patients with concomitant type 2 diabetes mellitus and asthma (47).

\section{ASSOCIATIONS WITH ASPECTS OF ASTHMA}

Expression and activation of some proteins have been found to be associated with clinical findings of asthma (Table 1) $(8,17,19)$. Activated $\beta_{1}$ integrin, specifically the intermediate-activity conformation recognized by monoclonal antibody (mAb) N29, on blood eosinophils correlates inversely with lung function in non-severe asthma $(52,54)$, or directly with the magnitude 
of the late-phase reaction in mild allergic asthma (36) or with exhaled NO [fraction of exhaled nitric oxide (FENO)], which reports airway inflammation, after inhaled corticosteroid (ICS) withdrawal (54). In addition, by receiver-operator characteristic (ROC) analysis, $\beta_{1}$ integrin activation, assessed with N29, predicts lowered pulmonary function in mild asthmatic patients (54). Intermediate-activity $\beta_{2}$, reported by the antibody KIM-127, is associated with the percentage of BAL eosinophils in patients with mild allergic asthma (34). Finally, activation of FcyRII (CD32) correlates with FENO in asthma (18).

TABLE 1 | Eosinophil surface proteins altered after antigen challenge or in the airway, or associated with asthma or aspects of asthma.

\begin{tabular}{|c|c|c|}
\hline Protein & Observation & Reference \\
\hline CD35 (CR1) & Downregulated in bronchoalveolar lavage (BAL) & $(20)$ \\
\hline CD44 & Upregulated after segmental lung antigen challenge, in BAL, or in sputum & $(21,22)$ \\
\hline CD45 & Upregulated in asthma & $(23)$ \\
\hline CD45R0 & Upregulated in asthma or mild-moderate asthma & $(23,24)$ \\
\hline CD48 & Upregulated in moderate asthma & $(25,26)$ \\
\hline CD58 & Upregulated in BAL & $(27)$ \\
\hline $\begin{array}{l}\text { CD63 (lysosome-associated membrane } \\
\text { protein 3) }\end{array}$ & Upregulated in BAL or sputum & $(27,28)$ \\
\hline CD66b (CEACAM8) & Upregulated in sputum & $(28)$ \\
\hline CD66e (CEACAM5) & Upregulated after segmental lung antigen challenge or in BAL & $(22)$ \\
\hline CD67 & Upregulated in BAL & (27) \\
\hline CD69 & Upregulated after whole-lung antigen challenge, in BAL, or in sputum & $(28-32)$ \\
\hline $\begin{array}{l}\text { CD137 (tumor necrosis factor receptor } \\
\text { superfamily member } 9 \text {, induced by } \\
\text { lymphocyte activation, } 4-1 \mathrm{BB} \text { ) }\end{array}$ & Upregulated in asthma & $(33)$ \\
\hline CD274 (programmed death ligand 1) & Upregulated in sputum & (28) \\
\hline$\alpha_{\llcorner}$integrin $(C D 11 a)$ & Upregulated in asthma or after segmental lung antigen challenge & $(34,35)$ \\
\hline$\alpha_{M}$ integrin (CD11b) & Upregulated after segmental lung antigen challenge, in BAL, or in sputum; Correlates inversely with $\mathrm{PC}_{20}$ & $\begin{array}{l}(20,27,28 \\
34,36-40)\end{array}$ \\
\hline$\alpha_{x}$ integrin (CD11c) & Upregulated in BAL or sputum & $(27,37)$ \\
\hline$\alpha_{D}$ integrin & Upregulated in BAL & $\begin{array}{l}(34,36 \\
41,42)\end{array}$ \\
\hline$\beta_{2}$ integrin (CD18) & Upregulated after segmental lung antigen challenge or in BAL & $(34,36)$ \\
\hline Aminopeptidase N (CD13) & Upregulated in BAL & $(43)$ \\
\hline$\beta c(C D 131)$ & Downregulated in BAL & $(44)$ \\
\hline FC $\alpha$ RI (CD89) & Upregulated in asthma & $(45)$ \\
\hline FC $\gamma R I I I(C D 16)$ & Upregulated in allergic asthma or after whole-lung antigen challenge & (46) \\
\hline Glucagon-like peptide-1R & Downregulated in allergic asthma & $(47)$ \\
\hline $\begin{array}{l}\text { Granulocyte monocyte-colony stimulating } \\
\text { factorR } \alpha \text { (CD116) }\end{array}$ & Upregulated in BAL & $(44,48)$ \\
\hline HLA-DR & Upregulated in BAL or sputum & $(20,37)$ \\
\hline Intercellular adhesion molecule-1 (CD54) & Upregulated in BAL or sputum & $(27,37)$ \\
\hline Interleukin (IL)-2R $\alpha$ (CD25) & Upregulated in BAL & (22) \\
\hline IL-3R $\alpha(C D 123)$ & Upregulated after segmental lung antigen challenge or in BAL & $(22,48)$ \\
\hline IL-5R $\alpha(C D 125)$ & Downregulated in BAL & $(44,48)$ \\
\hline IL-17RA & Upregulated in mild allergic asthma & (49) \\
\hline IL-17RB & Upregulated in mild allergic asthma & (49) \\
\hline L-selectin (CD62L) & Downregulated in BAL or sputum & $\begin{array}{c}(27,28,38 \\
40,50)\end{array}$ \\
\hline Neuropeptide S R & Upregulated in severe asthma & (51) \\
\hline P-selectin glycoprotein ligand-1 (CD162) & Upregulated after segmental lung antigen challenge or (48 h) after whole-lung antigen challenge & $(34,52)$ \\
\hline Semaphorin 7A (CD108) & Upregulated in BAL & (53) \\
\hline Activated $\alpha_{M}$ integrin & Highly activated conformation [reported by monoclonal antibody (mAb) CBRM1/5] in BAL or sputum & $(28,34,41)$ \\
\hline Activated $\beta_{1}$ integrin (CD29) & $\begin{array}{l}\text { Partially activated conformation (reported by mAb N29) increased in all or non-severe asthma, or after } \\
\text { segmental antigen challenge } \\
\text { Correlates negatively with forced expiratory volume in } 1 \mathrm{~s}\left(\mathrm{FEV}_{1}\right) \text { after or during withdrawal of inhaled corticosteroid } \\
\text { (ICS) in non-severe asthma and predicts decreased } \mathrm{FEV}_{1} \text { according to receiver-operator characteristic analysis } \\
\text { Correlates with fraction of exhaled nitric oxide (FENO) upon withdrawal of ICS in non-severe asthma } \\
\text { Correlates negatively with } \mathrm{FEV}_{1} \text { /forced vital capacity in younger non-severe asthmatic patients or in } \\
\text { phenotype clusters } 1-2 \text { (mild-moderate allergic asthma) } \\
\text { At } 48 \text { h, post-segmental lung antigen challenge correlates with decrease in FEV }{ }_{1} \text { during the late phase post- } \\
\text { whole-lung antigen challenge in mild allergic asthma } \\
\text { Highly activated conformation (reported by mAbs HUTS-21 and 9EG7) in BAL }\end{array}$ & $\begin{array}{c}(34,36,52 \\
54,55)\end{array}$ \\
\hline
\end{tabular}


TABLE 1 | Continued

\begin{tabular}{|c|c|c|}
\hline Protein & Observation & Reference \\
\hline Activated $\beta_{2}$ integrin & $\begin{array}{l}\text { Partially activated conformation (reported by mAb KIM-127) correlates with BAL eosinophil percentage in mild allergic } \\
\text { asthma } \\
\text { Highly activated conformation (reported by mAb24) in BAL }\end{array}$ & $(34,36)$ \\
\hline Activated Fc $\gamma R \|$ & $\begin{array}{l}\text { Activated conformation (reported by mAb A17 or A27) increased in mild asthma, after whole-lung antigen } \\
\text { challenge (in dual responders), or in BAL } \\
\text { Correlates with FENO in asthma }\end{array}$ & $(18,56,57)$ \\
\hline
\end{tabular}

Observations refer to expression level, usually determined by flow cytometry, and are, if not indicated otherwise, on human blood eosinophils. For abbreviations, please see list immediately after abstract.

The search strategy used Pubmed (https://www.ncbi.nlm.nih.gov/pubmed?db=PubMed) with various combinations of terms including "eosinophils" and "activation" and "asthma" and "state" or "status" or "biomarker" or "review" (the combination of only "eosinophils" and "activation" and "asthma" resulted in an unmanageable large number of publications). Publications covering years until 2017 were examined, with primary publications covering the years 2014-2017 being especially examined. Primary references covering years until 2013 were partly obtained from published review articles.

\section{DOWNREGULATION IN SEVERE ASTHMA OR AFTER ANTIGEN CHALLENGE}

Some surface proteins on blood eosinophils are downregulated in more severe or uncontrolled asthma compared to less severe disease (Table 2). These include CD44, a hyaluronan receptor, and CD48, whose levels are lower in poorly controlled or severe asthma compared to well-controlled or moderate disease $(21,25)$. Similarly, activated $\beta_{1}$ integrin, reported by mAb N29 (see above), is increased in non-severe, but not in severe, asthma compared to healthy control subjects (52).

A possible explanation for this phenomenon is a high degree of ongoing extravasation of the most activated eosinophils, i.e., those with the highest level of CD44, CD48, and $\beta_{1}$ integrin activation, in severe asthma. This is consistent with a role for CD44 in the movement of eosinophils to the airway in mice after antigen challenge $(8,68)$. Also, CD44, like P-selectin glycoprotein ligand (PSGL)-1, relocalizes on blood eosinophils after stimulation with IL- 5 or related cytokines, when the eosinophil changes shape and polarizes, and becomes concentrated at one end of the eosinophil in the nucleopod, which is a specialized uropod next to the nucleus (69). Such clustering of CD44 and other surface molecules may stimulate arrest and extravasation of eosinophils $(8,69)$. Similarly, uropod elongation, at the rear of a moving cell, is considered a crucial step in other leukocytes, including neutrophils and lymphocytes, before extravasation (70). Further, there is greater lung endothelial expression of vascular cell adhesion molecule (VCAM)-1, the ligand for $\alpha_{4} \beta_{1}$ integrin, in severe asthma, as observed in bronchial biopsies (71), which is compatible with efficient extravasation of eosinophils with activated $\alpha_{4} \beta_{1}$ integrin. The fraction of eosinophils that does not adhere to VCAM-1 in vitro has decreased $\beta_{1}$ activation, as reported by N29 (64), which also provides support for the scenario in which the eosinophils with a higher degree of $\alpha_{4} \beta_{1}$ activation are the ones that preferentially adhere to $\operatorname{VCAM}-1(8,17,64)$. Finally, N29 reactivity, surface-associated P-selectin, and level of PSGL-1 decrease transiently after whole-lung antigen challenge in patients with mild allergic asthma (Table 2) (52). P-selectin activates eosinophil $\beta_{1}$ integrin and induces the N29 epitope in vitro (64) and is associated with $\mathrm{N} 29$ reactivity in vivo (52). P-selectin is not synthesized by eosinophils (67). The P-selectin bound to the eosinophil surface is likely derived from activated
TABLE 2 | Eosinophil surface proteins downregulated in severe or poorly controlled asthma, or transiently after whole-lung antigen challenge.

\begin{tabular}{lll}
\hline Protein & Observation & Reference \\
\hline CD44 & $\begin{array}{l}\text { Downregulated in poorly controlled compared to } \\
\text { well-controlled asthma } \\
\text { Downregulated in severe compared to moderate } \\
\text { asthma }\end{array}$ \\
P-selectin & $\begin{array}{l}\text { Decreased transiently after whole-lung antigen } \\
\text { challenge }\end{array}$ \\
(CD62P) & $\begin{array}{l}\text { Decreased transiently after whole-lung antigen } \\
\text { P-selectin } \\
\text { glycoprotein }\end{array}$ & challenge \\
ligand-1 & \\
(CD162) & Intermediate-activity state (recognized by \\
Activated $\beta_{1}$ & monoclonal antibody N29) increased in non-severe \\
integrin & but not severe asthma \\
& $\begin{array}{l}\text { Decreased transiently after whole-lung antigen } \\
\text { challenge }\end{array}$
\end{tabular}

Observations refer to expression level, determined by flow cytometry, and are on human blood eosinophils.

$P$-selectin is not synthesized by eosinophils (67) but can be associated with the eosinophil surface and is likely derived from activated platelets $(52,64)$.

platelets associated with the eosinophils; a proportion (variable among different subjects) of eosinophils both in whole blood samples and purified eosinophils stain positively for the platelet marker $\alpha_{\text {IIb }}$ integrin (CD41) and P-selectin by flow cytometry or immunofluorescence microscopy $(52,64)$. The role of platelets, platelet activation, and platelet-eosinophil complexes in eosinophil recruitment and eosinophilic inflammation is the focus of another review within this Frontiers in Medicine Research Topic of "Pathogenic Advances and Therapeutic Perspectives for Eosinophilic Inflammation" and is described in more detail there (Shah S, Page CP, and Pitchford S: "Platelet-eosinophil interactions as a potential therapeutic target in allergic inflammation and asthma," submitted). Overall, the observations described above support the scenario that the most activated eosinophils; i.e., in this case, the cells with the highest degree of bound P-selectin, the highest level of the P-selectin counter-receptor PSGL-1, and activated $\alpha_{4} \beta_{1}$; extravasate, for instance, after whole-lung antigen challenge or in severe asthma.

In addition to possible extravasation of the most activated eosinophils in severe asthma and after whole-lung antigen 
challenge, it may also be, at least under some circumstances, that it is the most "activatable" cells that extravasate and the least "activatable" ones that remain in the circulation. High percentage of sputum eosinophils in asthmatic patients was found to be associated with low or no upregulation of $\alpha_{M}$ integrin or activation of FcyRII (CD32) on blood eosinophils in response to formylmethionine-leucyl-phenylalanine (fMLF) in vitro, whereas low sputum eosinophil count was associated with great $\alpha_{M}$ upregulation and CD32 activation in response to fMLF (72). These results indicate that the responsiveness of circulating eosinophils to a chemoattractant is lower in subjects with high sputum eosinophilia. This is possibly because the most responsive cells are continuously extravasating. An alternative or additional explanation may be that in patients with low sputum eosinophilia, the circulating eosinophils are not activated and are able to mount a great response to fMLF. On the other hand, in subjects with high sputum eosinophilia, the blood cells may already be at least partly activated (i.e., $\alpha_{M}$ already upregulated and CD32 altered to an activated conformation). In such a situation, fMLF may not achieve, or may achieve only little, further activation in vitro.

\section{RESPONSE TO INTERVENTION}

The expression or activation state of some proteins changes after pharmaceutical administration, e.g., with mepolizumab, an antibody against IL-5 (Table 3) (19). Anti-IL-5 mepolizumab causes decreased $\beta_{2}$ integrin, but not $\beta_{1}$ integrin, activation of blood eosinophils (Figure 1) (34). This indicates that the intermediate $\beta_{2}$ activation state on circulating eosinophils is the result of exposure to IL-5 in vivo and is consistent with in vitro data that IL- 5 causes $\beta_{2}$ but not $\beta_{1}$ activation, whereas P-selectin activates $\beta_{1}$ but not $\beta_{2}$ (64). The differential response to anti-IL-5 demonstrates that pharmaceutical intervention may inhibit one aspect of eosinophil activation but not another. Further, comparing blood eosinophils after segmental lung antigen challenge pre- and post-mepolizumab demonstrated that anti-IL-5 caused decreased levels of $\alpha_{\mathrm{L}}, \alpha_{\mathrm{M}}$, and $\beta_{2}$ integrins as well as PSGL-1 (34), indicating that the upregulation of these proteins that occurs on blood eosinophils after segmental lung antigen challenge is
IL-5-dependent. Finally, in contrast to the situation with blood eosinophils, anti-IL-5 did not affect the activation state of $\alpha_{M} \beta_{2}$ and the level of $\alpha_{L}, \alpha_{M}$, and $\beta_{2}$ on BAL eosinophils (34), indicating that the activation status of airway lumen eosinophils is independent of IL-5. This is consistent with the finding that BAL eosinophils have downregulated or no IL-5 receptor (Table 1) $(44,48)$, whereas they, in contrast, have upregulated IL-3 and granulocyte monocyte-colony stimulating factor (GM-CSF) receptors (Table $\mathbf{1})(22,44,48)$.

Whereas anti-IL-5 causes a decrease in blood eosinophil count $(9,10,34)$, administration of anti-IL-13 or anti-IL-4 receptor $\alpha$ causes an increase in blood eosinophils $(11,73,74)$. This observation is consistent with a scenario in which IL-13- or IL-4-induced factors, including VCAM-1, periostin, and eotaxins, promote eosinophil extravasation and trafficking (75-78). It would be interesting to know whether the circulating eosinophils after anti-IL-13/IL-4R $\alpha$ treatment have become more or less activated, or not altered, but the surface phenotype of blood eosinophils after anti-IL13/IL-4R $\alpha$ has not yet been reported. On one hand, one may imagine that they should become more activated, since ongoing extravasation of activated cells presumably has decreased, so activated cells instead may be expected to accumulate in the circulation. On the other hand, IL-13 or IL-4

TABLE 3 | Eosinophil surface proteins reported to respond to intervention in asthma.

\begin{tabular}{ll}
\hline Protein & Observation \\
\hline$\alpha_{L}$ integrin (CD11a) & $\begin{array}{l}\text { Decreased by anti-interleukin (IL)-5 (mepolizumab) } \\
\text { after segmental lung antigen challenge } \\
\text { Decreased by anti-IL-5 (mepolizumab) after } \\
\alpha_{M} \text { integrin (CD11b) }\end{array}$ \\
$\begin{array}{l}\text { segmental lung antigen challenge } \\
\beta_{2} \text { integrin (CD18) }\end{array}$ & Decreased by anti-IL-5 (mepolizumab) after \\
P-selectin glycoprotein & Decreased by anti-IL-5 (mepolizumab) after \\
ligand-1 (CD162) & segmental lung antigen challenge \\
Activated $\beta_{2}$ integrin & Intermediate-activity state (recognized by \\
& monoclonal antibody KIM-127) decreased by anti- \\
& IL-5 (mepolizumab)
\end{tabular}

Observations refer to expression level, determined by flow cytometry, and are on blood eosinophils in mild allergic asthma (34).
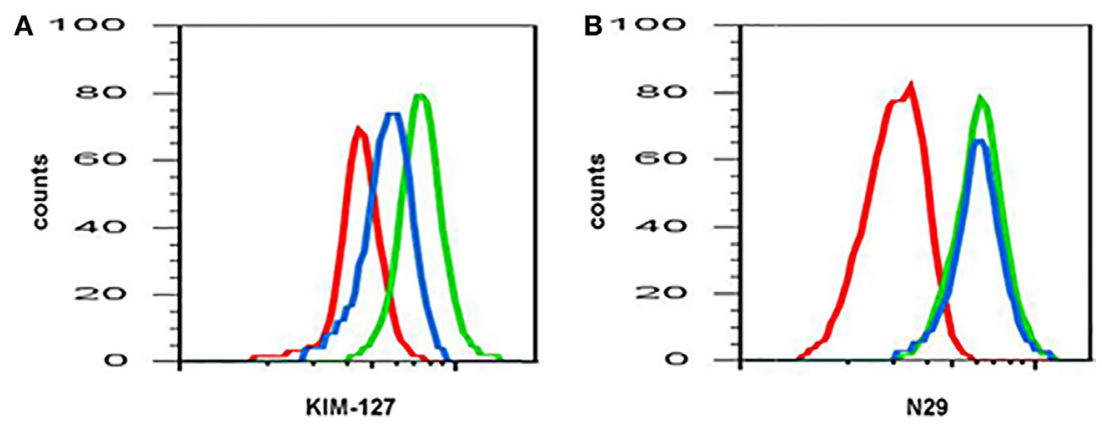

FIGURE 1 | Anti-interleukin (IL)-5 (mepolizumab) decreases $\beta_{2}$ but not $\beta_{1}$ integrin activation on blood eosinophils. Reactivity of monoclonal antibody (A) KIM-127 (to the intermediate-activity state of $\beta_{2}$ integrin), and (B) N29 (to the intermediate-activity state of $\beta_{1}$ integrin) on blood eosinophils before (green) and after (blue) anti-IL-5 mepolizumab administration. Red, isotype control. A representative subject with mild allergic asthma from Ref. (34). 
themselves may stimulate some aspects of eosinophil activation, e.g., they have been reported to upregulate CD69 (8), indicating that anti-IL-13/IL-4R $\alpha$ may lead to lower activation of blood eosinophils, or that at least some aspects of eosinophil activation may be decreased.

Recently, a mathematical modeling approach was taken in order to understand the effect of anti-IL therapy on eosinophil activation and dynamics (79). The mathematical model of Karelina and colleagues predicts a rapid decrease in total and activated eosinophil counts in blood and airways after anti-IL-5 mepolizumab administration. The decrease in blood eosinophils in the model is consistent with the literature, whereas the model appears to predict a greater proportional decrease in airway eosinophil counts than what actually happens after mepolizumab $(9,10,34)$. The decrease in blood eosinophil activation in the model is consistent with the observed decrease in $\beta_{2}$ integrin activation (see here above and Figure 1) (34). However, the decrease in activated eosinophils in the airway in the model is not consistent with the observed lack of effect on integrin activation and expression levels on BAL eosinophils after mepolizumab (34). This disagreement between the model and observations may be because the model assumes that IL-5 is involved in the activation of airway eosinophils, whereas in reality, it may not be. Other factors such as IL-3 may be essential or compensate for IL-5 to stimulate and maintain airway eosinophil activation (see above and more below). Further, the model correctly predicts an increase in total eosinophils in blood and a decrease in the airway for anti-IL-13 therapies. Finally, it also predicts an increase in the number of activated eosinophils in blood after anti-IL-13, something which has not been reported but would be interesting to investigate, as mentioned above.

\section{A MODEL FOR EOSINOPHIL ACTIVATION STATES IN THE CIRCULATION AND THE AIRWAY IN ASTHMA}

The results from the studies on integrins discussed above suggest that there is variation in the activation status of circulating eosinophils among different individuals (8). Healthy persons and some patients with asthma display inactive $\beta_{1}$ integrins, patients with non-severe asthma have partially activated $\beta_{1}$ and $\beta_{2}$ integrins to different degrees, and patients with severe asthma have inactive or less activated $\beta_{1}$ integrins (8). The latter occurs likely due to arrest and extravasation of activated eosinophils (see model in Figure 2 and references in the figure legend). Similarly, a scenario for FcyRII (CD32) activation on blood eosinophils has been described, where the degree of activation initially is elevated along with a higher level of systemic inflammation and then lower at the greatest degree of systemic inflammation $(8,18)$.

Airway lumen eosinophils, as sampled during BAL, have highly activated and upregulated $\alpha_{\mathrm{M}} \beta_{2}$ and highly activated $\beta_{1}$ $(34,36)$, downregulated or no IL-5 receptor $(44,48)$, as well as upregulated IL-3 receptor $(22,48)$ and upregulated and highly activated FcyRII (CD32) (56). As the integrin activation state and levels on BAL eosinophils are not affected by anti-IL-5 (see above in Section "Response to Intervention") and BAL eosinophils lack IL-5-receptor, the airway lumen eosinophil phenotype is presumably the result of and maintained by other stimuli than IL-5, e.g., the related cytokines IL-3 and/or GM-CSF. IL-3 is the most likely responsible factor, since it, compared to IL-5, causes a higher degree of prolonged upregulation and activation of $\alpha_{M} \beta_{2}$ and CD32 (81).

The activation status of the lung tissue eosinophil in asthma is largely unknown. As depicted in Figure 2, eosinophils in lung tissue likely are adherent to or migrating in the ECM, e.g., by interacting with the ECM protein periostin, which is upregulated and associated with eosinophil recruitment to the airway in type 2 immunity-high asthma (82-86). Eosinophil adhesion to and motility on periostin is mediated by $\alpha_{\mathrm{M}} \beta_{2}$ integrin and stimulated by nanogram per milliliter IL-5 $(75,80)$, which induces the high-activity conformation of $\alpha_{\mathrm{M}} \beta_{2}(41,64)$. Thus, assuming that tissue eosinophils interact with periostin, they likely have highly activated $\alpha_{\mathrm{M}} \beta_{2}$. Whether tissue eosinophils express (like blood eosinophils) or lack (like BAL eosinophils) IL-5R, and in the latter case are stimulated and maintained active by GM-CSF or IL-3, appears uncertain and would be very interesting to determine.

Some recent very interesting articles studied mouse lung tissue eosinophils and partly also human lung tissue eosinophils $(87,88)$. Abdala Valencia and colleagues reported that, after antigen challenge, mouse lung tissue eosinophils shifted from a surface phenotype with intermediate expression of Siglec-F and no or very low $\alpha_{\mathrm{x}}$ integrin (CD11c) to a Siglec-F-high/CD11c-low phenotype, and that BAL eosinophils were of the latter phenotype (87). Mesnil and others found that mouse steady-state pulmonary resident eosinophils were IL-5-independent and expressed an intermediate level of Siglec-F (in consistency with the first tissue phenotype in the Abdala Valencia publication), high L-selectin (CD62L), and low CD101 (immunoglobulin superfamily member 2) (88). After antigen challenge, these resident tissue cells were accompanied by newly recruited inflammatory tissue eosinophils, which were IL-5-dependent, Siglec-F-high, CD62L-low, and CD101-high $(88,89)$. In addition, Mesnil and colleagues determined that parenchymal resident eosinophils found in non-asthmatic human lungs had a CD62L-high, IL-3R-low phenotype, which was distinct from the phenotype of asthmatic sputum eosinophils, being CD62L-low/IL-3R-high (88). Their description of sputum eosinophils is consistent with earlier findings on sputum and BAL eosinophils (Table 1). Thus, both in humans and mice, lung tissue eosinophils may be of two phenotypes, one resident phenotype unrelated to asthma and different from the asthmatic airway lumen eosinophil phenotype, and one inflammatory phenotype recruited in asthma and similar or more similar to the airway lumen phenotype. A more detailed description of the tissue-resident eosinophils is given in another review within this Research Topic (Marichal T, Mesnil C, and Bureau F: "Homeostatic eosinophils: characteristics and functions," submitted). As indicated above, a more complete description of the inflammatory lung tissue eosinophil phenotype in asthma and a comparison to the blood and airway lumen phenotypes in asthma are warranted, e.g., to answer questions about integrin activation status of the lung tissue eosinophils and whether they express IL-5R. 


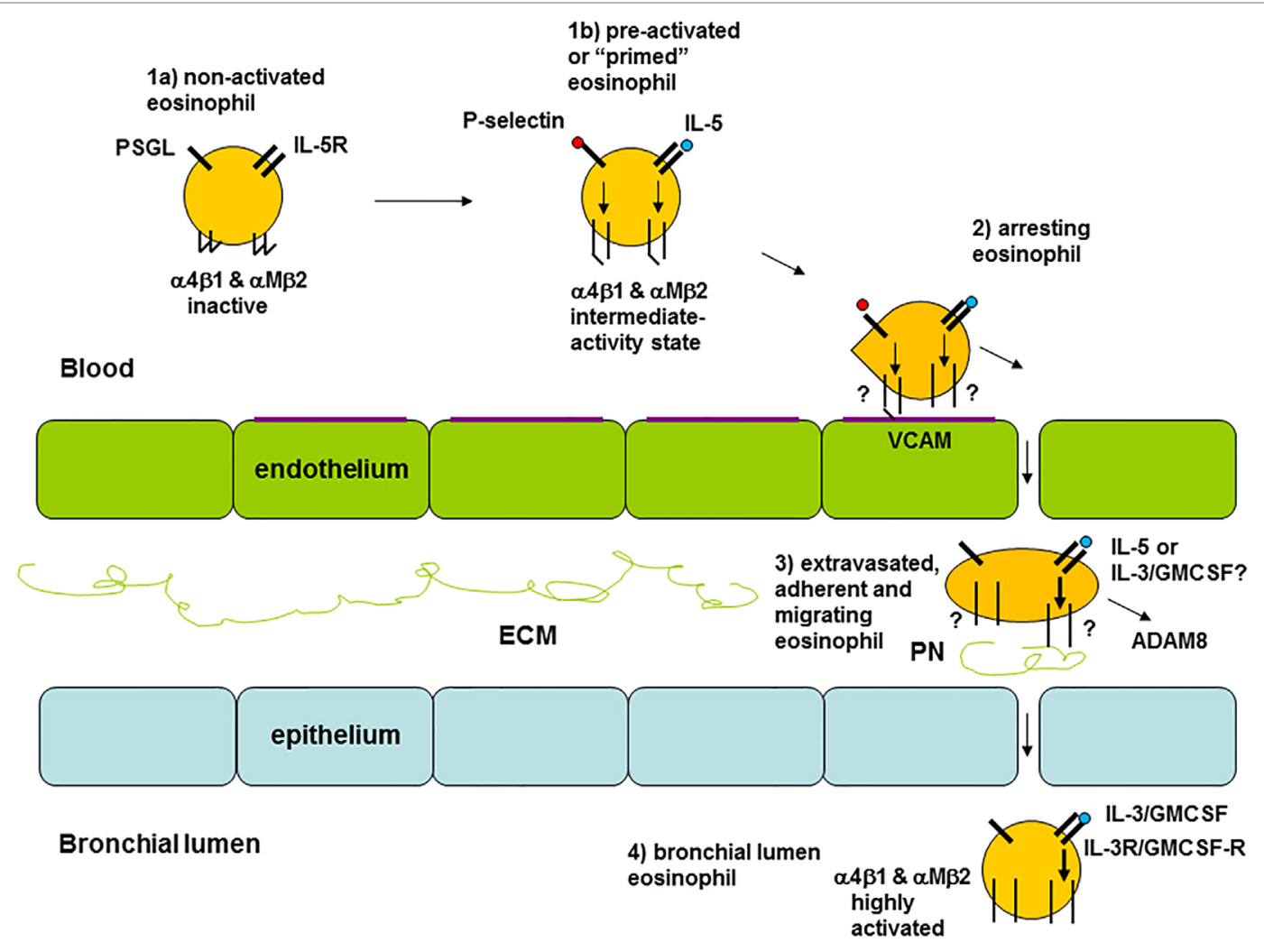

FIGURE 2 | Model of eosinophil activation states in asthma. (1a) Circulating non-activated eosinophil with $\alpha_{4} \beta_{1}$ and $\alpha_{M} \beta_{2}$ integrins in the inactive conformation or state, as found in normal subjects, some patients with non-severe asthma, or as observed in severe asthmatic patients likely because of a high degree of extravasation of activated eosinophils. (1b) Pre-activated or "primed," partly activated, circulating eosinophil with $\alpha_{4} \beta_{1}$ and $\alpha_{m} \beta_{2}$ in the intermediate-activity state, as a result of signaling triggered by P-selectin (likely derived from activated platelets, see the main text) and low concentration of interleukin (IL)-5, respectively, as found primarily in some subjects with non-severe asthma. (2) Eosinophil arresting on activated endothelium in asthma with $\alpha_{4} \beta_{1}$ and $\alpha_{M} \beta_{2}$ in unknown state, with $\alpha_{4} \beta_{1}$ primarily mediating arrest on vascular cell adhesion molecule (VCAM)- 1 with a possible minor contribution of $\alpha_{M} \beta_{2}$. (3) Extravasated, adherent, and migrating tissue eosinophil in asthma with $\alpha_{4} \beta_{1}$ and $\alpha_{M} \beta_{2}$ likely in the high-activity state, with high-activity $\alpha_{M} \beta_{2}$, resulting from cytokine-triggered signaling, mediating interaction with the adhesive and pro-migratory extracellular matrix (ECM) protein periostin, and the eosinophil-releasing disintegrin and metalloproteinase (ADAM) 8 involved in PN degradation and cell migration. (4) Bronchial lumen highly activated eosinophil in asthma with $\alpha_{4} \beta_{1}$ and $\alpha_{M} \beta_{2}$ in the high-activity state and with downregulated or no IL-5 receptor, and with high-activity $\alpha_{m} \beta_{2}$ resulting from IL-3 and/or granulocyte monocyte-colony stimulating factor (GM-CSF)-triggered signaling. Modified and extended from Ref. (8) and also based on Ref. $(34,36,44,69,80)$. Note: this model focuses on the activation states of integrins and on receptors for IL-5 family cytokines. It is not intended to be a full rendition of all possible factors involved in eosinophil recruitment. For instance, glycoproteins and glycans, including endothelial surface selectins and their role in eosinophil rolling, are covered in other reviews within this Research Topic (O'Sullivan JA, Carroll DJ, and Bochner BS: "Glycobiology of eosinophilic inflammation: contributions of siglecs, glycans, and other glycan-binding proteins," submitted; and Rao AP, Ge XN, and Sriramarao P: "Regulation of eosinophil recruitment and activation by galectins in allergic asthma," accepted). Further, chemokines and their receptors are the focus of yet another review (Larose M-C, Archambault A-S, Provost V, Laviolette M, and Flamand N: "Regulation of eosinophil and group 2 innate lymphoid cell trafficking in asthma," submitted).

\section{CONCLUSION AND PERSPECTIVES}

In this article, a number of proteins on the cell surface that have been suggested to mark eosinophil activation and are altered after antigen challenge or in the airway, or are associated with asthma or aspects of asthma, as well as a subset of these proteins that respond to intervention are reviewed. Partial $\beta_{1}$ integrin activation on blood eosinophils is associated with impaired pulmonary function or airway inflammation, and partial $\beta_{2}$ integrin activation is associated with airway eosinophilia in non-severe asthma. The associations do not occur in severe asthma, presumably due to greater extravasation of pre-activated eosinophils in severe disease. Airway lumen eosinophils have highly activated integrins and other changes in surface proteins compared to blood eosinophils. The activation state(s) of eosinophils in human lung tissue, although likely very important in asthma, is largely unknown but has begun to be studied.

The utility of the potential biomarkers of eosinophil activation in blood, a clinically accessible compartment, e.g., as correlators with or reporters of aspects of asthma, particularly severe asthma, needs to be explored further in translational and clinical studies. Although an occasional marker increases with asthma severity, some markers are downregulated in severe disease compared to non-severe disease. Possible reasons for the latter phenomenon are discussed above in the text. Still, since some of the markers respond to anti-IL-5, these or other IL-5-dependent markers may be predictors of response to intervention. The effect of other therapies, e.g., anti-IL-13/IL-4R, on surface markers of eosinophil activation has not been reported 
but is a very interesting question. For instance, it may be interesting to examine whether potential alterations in eosinophil surface activation markers after various interventions may turn out to be associated with disease improvement, or possibly with decreased or increased risks for adverse eosinophil-related events. Finally, the potential relevance of these biomarkers in other eosinophilic and allergic diseases (19) also requires future exploration.

\section{AUTHOR CONTRIBUTIONS}

MJ conceived and designed, and interpreted the literature for this review; drafted and revised the manuscript, and approved the final version.

\section{REFERENCES}

1. Thomas A, Busse WW. The evolving role of eosinophils in asthma. In: Lee JJ, Rosenberg HF, editors. Eosinophils in Health and Disease. Amsterdam: Elsevier (2013). p. 448-62.

2. Rosenberg HF, Dyer KD, Foster PS. Eosinophils: changing perspectives in health and disease. Nat Rev Immunol (2013) 13(1):9-22. doi:10.1038/nri3341

3. Haldar P, Pavord ID, Wardlaw AJ. Insights into the pathogenesis of asthma and other eosinophil-mediated diseases from antagonists of interleukin- 5 and its receptor. In: Lee JJ, Rosenberg HF, editors. Eosinophils in Health and Disease. Amsterdam: Elsevier (2013). p. 579-87.

4. Nair P. Eosinophil-targeted treatment of asthma. In: Lee JJ, Rosenberg HF, editors. Eosinophils in Health and Disease. Amsterdam: Elsevier (2013). p. $462-5$.

5. Fulkerson PC, Rothenberg ME. Targeting eosinophils in allergy, inflammation and beyond. Nat Rev Drug Discov (2013) 12(2):117-29. doi:10.1038/nrd3838

6. Pavord ID. Eosinophilic phenotypes of airway disease. Ann Am Thorac Soc (2013) 10(Suppl):S143-9. doi:10.1513/AnnalsATS.201306-168AW

7. Haldar P, Pavord ID, Shaw DE, Berry MA, Thomas M, Brightling CE, et al. Cluster analysis and clinical asthma phenotypes. Am J Respir Crit Care Med (2008) 178(3):218-24. doi:10.1164/rccm.200711-1754OC

8. Johansson MW. Activation states of blood eosinophils in asthma. Clin Exp Allergy (2014) 44(4):482-98. doi:10.1111/cea.12292

9. Haldar P, Brightling CE, Hargadon B, Gupta S, Monteiro W, Sousa A, et al. Mepolizumab and exacerbations of refractory eosinophilic asthma. $N$ Engl J Med (2009) 360(10):973-84. doi:10.1056/NEJMoa0808991

10. Nair P, Pizzichini MM, Kjarsgaard M, Inman MD, Efthimiadis A, Pizzichini E, et al. Mepolizumab for prednisone-dependent asthma with sputum eosinophilia. N Engl J Med (2009) 360(10):985-93. doi:10.1056/NEJMoa0805435

11. Arron JR, Townsend MJ, Keir ME, Yaspan BL, Chan AC. Stratified medicine in inflammatory disorders: from theory to practice. Clin Immunol (2015) 161(1):11-22. doi:10.1016/j.clim.2015.04.006

12. Flood-Page P, Menzies-Gow A, Phipps S, Ying S, Wangoo A, Ludwig MS, et al. Anti-IL-5 treatment reduces deposition of ECM proteins in the bronchial subepithelial basement membrane of mild atopic asthmatics. JClin Invest (2003) 112(7):1029-36. doi:10.1172/JCI17974

13. Kay AB, Phipps S, Robinson DS. A role for eosinophils in airway remodelling in asthma. Trends Immunol (2004) 25(9):477-82. doi:10.1016/j.it.2004.07.006

14. Pavord ID, Korn S, Howarth P, Bleecker ER, Buhl R, Keene ON, et al. Mepolizumab for severe eosinophilic asthma (DREAM): a multicentre, double-blind, placebo-controlled trial. Lancet (2012) 380(9842):651-9. doi:10.1016/S0140-6736(12)60988-X

15. Rosenberg HF, Phipps S, Foster PS. Eosinophil trafficking in allergy and asthma. J Allergy Clin Immunol (2007) 119(6):1303-10. doi:10.1016/j. jaci.2007.03.048

16. Barthel SR, Johansson MW, McNamee DM, Mosher DF. Roles of integrin activation in eosinophil function and the eosinophilic inflammation of asthma. J Leukoc Biol (2008) 83(1):1-12. doi:10.1189/jlb.0607344

17. Johansson MW, Mosher DF. Integrin activation states and eosinophil recruitment in asthma. Front Pharmacol (2013) 4:33. doi:10.3389/fphar.2013.00033

\section{ACKNOWLEDGMENTS}

This review and our research on eosinophil activation status were supported by Program Project grant P01 HL088594 and the Severe Asthma Research Program grants R01 HL069116 and 1U10 HL109168 from the National Institutes of Health. I thank Deane Mosher for excellent discussions. I am grateful to many others, including Nizar Jarjour, Loren Denlinger, Sameer Mathur, Ronald Sorkness, and William Busse, without whom our studies on human subjects would not have been possible; and to them, Stephane Esnault, Elizabeth Kelly, Michael Evans, and Gina Crisafi for discussions and steadfast research, administrative, and statistical support and advice.

18. Koenderman L. Priming: a critical step in the control of eosinophil activation. In: Lee JJ, Rosenberg HF, editors. Eosinophils in Health and Disease. Amsterdam: Elsevier (2013). p. 170-9.

19. Metcalfe DD, Pawankar R, Ackerman SJ, Akin C, Clayton F, Falcone FH, et al. Biomarkers of the involvement of mast cells, basophils and eosinophils in asthma and allergic diseases. World Allergy Organ J (2016) 9:7. doi:10.1186/ s40413-016-0094-3

20. Sedgwick JB, Calhoun WJ, Vrtis RF, Bates ME, McAllister PK, Busse WW. Comparison of airway and blood eosinophil function after in vivo antigen challenge. J Immunol (1992) 149(11):3710-8.

21. Sano K, Yamauchi K, Hoshi H, Honma M, Tamura G, Shirato K. CD44 expression on blood eosinophils is a novel marker of bronchial asthma. Int Arch Allergy Immunol (1997) 114(Suppl 1):67-71. doi:10.1159/000237722

22. Bates ME, Liu LY, Esnault S, Stout BA, Fonkem E, Kung V, et al. Expression of interleukin-5- and granulocyte macrophage-colony-stimulating factorresponsive genes in blood and airway eosinophils. Am J Respir Cell Mol Biol (2004) 30(5):736-43. doi:10.1165/rcmb.2003-0234OC

23. Blaylock MG, Lipworth BJ, Dempsey OJ, Duncan CJ, Lee DK, Lawrie A, et al. Eosinophils from patients with asthma express higher levels of the panleucocyte receptor CD45 and the isoform CD45RO. Clin Exp Allergy (2003) 33(7):936-41. doi:10.1046/j.1365-2222.2003.01697.x

24. Sakamoto S, Oki K, Takahashi H, Arakawa Y, Sugita H, Hirano H, et al. Comparison of surface antigens on eosinophils from patients with eosinophilia. Int Arch Allergy Immunol (1996) 111(Suppl 1):26-8. doi:10.1159/ 000237410

25. Gangwar RS, Minai-Fleminger Y, Seaf M, Gutgold A, Shikotra A, Barber C, et al. CD48 on blood leukocytes and in serum of asthma patients varies with severity. Allergy (2017) 72(6):888-95. doi:10.1111/all.13082

26. Munitz A, Bachelet I, Eliashar R, Khodoun M, Finkelman FD, Rothenberg ME, et al. CD48 is an allergen and IL-3-induced activation molecule on eosinophils. J Immunol (2006) 177(1):77-83. doi:10.4049/jimmunol.177.1.77

27. Mengelers HJ, Maikoe T, Brinkman L, Hooibrink B, Lammers JW, Koenderman L. Immunophenotyping of eosinophils recovered from blood and BAL of allergic asthmatics. Am J Respir Crit Care Med (1994) 149:345-51. doi:10.1164/ajrccm.149.2.8306028

28. Tak T, Hilvering B, Tesselaar K, Koenderman L. Similar activation state of neutrophils in sputum of asthma patients irrespective of sputum eosinophilia. Clin Exp Immunol (2015) 182(2):204-12. doi:10.1111/cei. 12676

29. Hartnell A, Robinson DS, Kay AB, Wardlaw AJ. CD69 is expressed by human eosinophils activated in vivo in asthma and in vitro by cytokines. Immunology (1993) 80(2):281-6.

30. Matsumoto K, Appiah-Pippim J, Schleimer RP, BickelCA, Beck LA, Bochner BS. CD44 and CD69 represent different types of cell-surface activation markers for human eosinophils. Am J Respir Cell Mol Biol (1998) 18(6):860-6. doi:10.1165/ajrcmb.18.6.3159

31. Julius P, Luttmann W, Knoechel B, Kroegel C, Matthys H, Virchow JC Jr. CD69 surface expression on human lung eosinophils after segmental allergen provocation. Eur Respir J (1999) 13(6):1253-9. doi:10.1183/09031936.99.13 612609 
32. Pignatti P, Perfetti L, Galdi E, Pozzi V, Bossi A, Biale C, et al. Increased CD69 expression on peripheral blood eosinophils after specific inhalation challenge. Allergy (2002) 57(5):411-6. doi:10.1034/j.1398-9995.2002.23454.x

33. Heinisch IV, Bizer C, Volgger W, Simon HU. Functional CD137 receptors are expressed by eosinophils from patients with IgE-mediated allergic responses but not by eosinophils from patients with non-IgE-mediated eosinophilic disorders. J Allergy Clin Immunol (2001) 108(1):21-8. doi:10.1067/ mai.2001.116864

34. Johansson MW, Gunderson KA, Kelly EA, Denlinger LC, Jarjour NN, Mosher DF. Anti-IL-5 attenuates activation and surface density of beta(2) -integrins on circulating eosinophils after segmental antigen challenge. Clin Exp Allergy (2013) 43(3):292-303. doi:10.1111/j.1365-2222.2012.04065.x

35. Lantero S, Alessandri G, Spallarossa D, Scarso L, Rossi GA. LFA-1 expression by blood eosinophils is increased in atopic asthmatic children and is involved in eosinophil locomotion. Eur Respir J (1998) 12(5):1094-8. doi:10.1183/090 31936.98.12051094

36. Johansson MW, Kelly EA, Busse WW, Jarjour NN, Mosher DF. Up-regulation and activation of eosinophil integrins in blood and airway after segmental lung antigen challenge. J Immunol (2008) 180(11):7622-35. doi:10.4049/ jimmunol.180.11.7622

37. Hansel TT, Braunstein JB, Walker C, Blaser K, Bruijnzeel PL, Virchow JC Jr, et al. Sputum eosinophils from asthmatics express ICAM-1 and HLA-DR. Clin Exp Immunol (1991) 86(2):271-7. doi:10.1111/j.1365-2249.1991.tb05809.x

38. Georas SN, Liu MC, Newman W, Dawson Beall L, Stealey BA, Bochner BS. Altered adhesion molecule expression and endothelial cell activation accompany the recruitment of human granulocytes to the lung after segmental antigen challenge. Am J Respir Cell Mol Biol (1992) 7:261-9. doi:10.1165/ ajrcmb/7.3.261

39. Kroegel C, Liu MC, Hubbard WC, Lichtenstein LM, Bochner BS. Blood and bronchoalveolar eosinophils in allergic subjects after segmental antigen challenge: surface phenotype, density heterogeneity, and prostanoid production. J Allergy Clin Immunol (1994) 93(4):725-34. doi:10.1016/00916749(94)90252-6

40. in 't Veen JC, Grootendorst DC, Bel EH, Smits HH, Van Der Keur M, Sterk PJ, et al. CD11b and L-selectin expression on eosinophils and neutrophils in blood and induced sputum of patients with asthma compared with normal subjects. Clin Exp Allergy (1998) 28(5):606-15. doi:10.1046/j.1365-2222.1998.00279.x

41. Barthel SR, Jarjour NN, Mosher DF, Johansson MW. Dissection of the hyperadhesive phenotype of airway eosinophils in asthma. Am J Respir Cell Mol Biol (2006) 35(3):378-86. doi:10.1165/rcmb.2006-0027OC

42. Grayson MH, Van der Vieren M, Sterbinsky SA, Gallatin WM, Hoffman PA, Staunton DE, et al. adb2 Integrin is expressed on human eosinophils and functions as an alternative ligand for vascular cell adhesion molecule 1 (VCAM-1). J Exp Med (1998) 188(11):2187-91. doi:10.1084/jem.188.11.2187

43. Braun RK, Foerster M, Workalemahu G, Haefner D, Kroegel C, Walker C. Differential regulation of aminopeptidase N (CD13) by transendothelial migration and cytokines on human eosinophils. Exp Lung Res (2003) 29(2):59-77. doi:10.1080/01902140303766

44. Liu LY, Sedgwick JB, Bates ME, Vrtis RF, Gern JE, Kita H, et al. Decreased expression of membrane IL-5 receptor alpha on human eosinophils: I. Loss of membrane IL-5 receptor alpha on airway eosinophils and increased soluble IL-5 receptor alpha in the airway after allergen challenge. J Immunol (2002) 169(11):6452-8. doi:10.4049/jimmunol.169.11.6452

45. Monteiro RC, Hostoffer RW, CooperMD, BonnerJR, GartlandGL, KubagawaH. Definition of immunoglobulin A receptors on eosinophils and their enhanced expression in allergic individuals. J Clin Invest (1993) 92(4):1681-5. doi:10.1172/JCI116754

46. Davoine F, Lavigne S, Chakir J, Ferland C, Boulay ME, Laviolette M. Expression of FcgammaRIII (CD16) on human peripheral blood eosinophils increases in allergic conditions. J Allergy Clin Immunol (2002) 109(3):463-9. doi:10.1067/ mai.2002.121952

47. Mitchell PD, Salter BM, Oliveria JP, El-Gammal A, Tworek D, Smith SG, et al. Glucagon-like peptide-1 receptor expression on human eosinophils and its regulation of eosinophil activation. Clin Exp Allergy (2017) 47(3):331-8. doi:10.1111/cea.12860

48. Esnault S, Kelly EA, Shen ZJ, Johansson MW, Malter JS, Jarjour NN. IL-3 maintains activation of the p90S6K/RPS6 pathway and increases translation in human eosinophils. J Immunol (2015) 195(6):2529-39. doi:10.4049/ jimmunol.1500871
49. Tang W, Smith SG, Beaudin S, Dua B, Howie K, Gauvreau G, et al. IL-25 and IL-25 receptor expression on eosinophils from subjects with allergic asthma. Int Arch Allergy Immunol (2014) 163(1):5-10. doi:10.1159/000355331

50. Mengelers HJ, Maikoe T, Hooibrink B, Kuypers TW, Kreukniet J, Lammers JW, et al. Down modulation of L-selectin expression on eosinophils recovered from bronchoalveolar lavage fluid after allergen provocation. Clin Exp Allergy (1993) 23(3):196-204. doi:10.1111/j.1365-2222.1993.tb00882.x

51. Ilmarinen P, James A, Moilanen E, Pulkkinen V, Daham K, Saarelainen S, et al. Enhanced expression of neuropeptide S (NPS) receptor in eosinophils from severe asthmatics and subjects with total IgE above 100IU/ml. Peptides (2014) 51:100-9. doi:10.1016/j.peptides.2013.10.030

52. Johansson MW, Han ST, Gunderson KA, Busse WW, Jarjour NN, Mosher DF. Platelet activation, P-selectin, and eosinophil betal-integrin activation in asthma. Am J Respir Crit Care Med (2012) 185(5):498-507. doi:10.1164/ rccm.201109-1712OC

53. Esnault S, Kelly EA, Johansson MW, Liu LY, Han ST, Akhtar M, et al. Semaphorin 7A is expressed on airway eosinophils and upregulated by IL-5 family cytokines. Clin Immunol (2014) 150(1):90-100. doi:10.1016/j. clim.2013.11.009

54. Johansson MW, Barthel SR, Swenson CA, Evans MD, Jarjour NN, Mosher DF, et al. Eosinophil beta 1 integrin activation state correlates with asthma activity in a blind study of inhaled corticosteroid withdrawal. J Allergy Clin Immunol (2006) 117(6):1502-4. doi:10.1016/j.jaci.2006.02.032

55. Johansson MW, Han S-T, Gunderson KA, Montgomery RR, Busse WW, Jarjour NN, et al. Platelet activation, P-selectin mobilization, and eosinophil betal integrin activation occur in asthma and are associated with clinical phenotypes [abstract]. Am J Respir Crit Care Med (2011) 183:A4335. doi:10.1164/ ajrccm-conference.2011.183.1_MeetingAbstracts.A4335

56. Luijk B, Lindemans CA, Kanters D, van der Heijde R, Bertics P, Lammers JW, et al. Gradual increase in priming of human eosinophils during extravasation from peripheral blood to the airways in response to allergen challenge. J Allergy Clin Immunol (2005) 115(5):997-1003. doi:10.1016/j.jaci.2005.02.002

57. Kanters D, ten Hove W, Luijk B, van Aalst C, Schweizer RC, Lammers JW, et al. Expression of activated $\mathrm{Fc}$ gamma RII discriminates between multiple granulocyte-priming phenotypes in peripheral blood of allergic asthmatic subjects. J Allergy Clin Immunol (2007) 120(5):1073-81. doi:10.1016/j.jaci. 2007.06.021

58. Driss V, Legrand F, Capron M. Eosinophil receptor profile. In: Lee JJ, Rosenberg HF, editors. Eosinophils in Health and Disease. Amsterdam: Elsevier (2013). p. 30-8.

59. Vijverberg SJ, Hilvering B, Raaijmakers JA, Lammers JW, Maitland-van der Zee AH, Koenderman L. Clinical utility of asthma biomarkers: from bench to bedside. Biologics (2013) 7:199-210. doi:10.2147/BTT.S29976

60. Carr TF, Berdnikovs S, Simon HU, Bochner BS, Rosenwasser LJ. Eosinophilic bioactivities in severe asthma. World Allergy Organ J (2016) 9:21. doi:10.1186/ s40413-016-0112-5

61. Zissler UM, Esser-von Bieren J, Jakwerth CA, Chaker AM, Schmidt-Weber CB. Current and future biomarkers in allergic asthma. Allergy (2016) 71(4):475-94. doi:10.1111/all.12828

62. Denlinger LC, Kelly EA, Dodge AM, McCartney JG, Meyer KC, Cornwell $\mathrm{RD}$, et al. Safety of and cellular response to segmental bronchoprovocation in allergic asthma. PLoS One (2013) 8(1):e51963. doi:10.1371/journal.pone.0051963

63. Gauvreau GM, Evans MY. Allergen inhalation challenge: a human model of asthma exacerbation. Contrib Microbiol (2007) 14:21-32. doi:10.1159/ 0000107052

64. Johansson MW, Mosher DF. Activation of betal integrins on blood eosinophils by P-selectin. Am J Respir Cell Mol Biol (2011) 45(4):889-97. doi:10.1165/ rcmb.2010-0402OC

65. SedgwickJB, Shikama Y, Nagata M, Brener K, Busse WW. Effect of isolation protocol on eosinophil function: Percoll gradients versus immunomagnetic beads. J Immunol Methods (1996) 198(1):15-24. doi:10.1016/0022-1759(96)00139-1

66. Johnsson M, Bove M, Bergquist H, Olsson M, Fornwall S, Hassel K, et al. Distinctive blood eosinophilic phenotypes and cytokine patterns in eosinophilic esophagitis, inflammatory bowel disease and airway allergy. J Innate Immun (2011) 3(6):594-604. doi:10.1159/000331326

67. Shen ZJ, Hu J, Esnault S, Dozmorov I, Malter JS. RNA Seq profiling reveals a novel expression pattern of TGF-beta target genes in human blood eosinophils. Immunol Lett (2015) 167(1):1-10. doi:10.1016/j.imlet.2015.06.012 
68. Katoh S, Matsumoto N, Kawakita K, Tominaga A, Kincade PW, Matsukura S. A role for CD44 in an antigen-induced murine model of pulmonary eosinophilia. J Clin Invest (2003) 111(10):1563-70. doi:10.1172/JCI16583

69. Han ST, Mosher DF. IL-5 induces suspended eosinophils to undergo unique global reorganization associated with priming. Am J Respir Cell Mol Biol (2014) 50(3):654-64. doi:10.1165/rcmb.2013-0181OC

70. Hind LE, Vincent WJ, Huttenlocher A. Leading from the back: the role of the uropod in neutrophil polarization and migration. Dev Cell (2016) 38(2):161-9. doi:10.1016/j.devcel.2016.06.031

71. Ramos-Barbon D, Fraga-Iriso R, Brienza NS, Montero-Martinez C, VereaHernando H, Olivenstein R, et al. T Cells localize with proliferating smooth muscle alpha-actin + cell compartments in asthma. Am J Respir Crit Care Med (2010) 182(3):317-24. doi:10.1164/rccm.200905-0745OC

72. Hilvering B, Vijverberg SJ, Jansen J, Houben L, Schweizer RC, Go S, et al. Diagnosing eosinophilic asthma using a multivariate prediction model based on blood granulocyte responsiveness. Allergy (2016). doi:10.1111/ all. 13117

73. Hanania NA, Korenblat P, Chapman KR, Bateman ED, Kopecky P, Paggiaro P, et al. Efficacy and safety of lebrikizumab in patients with uncontrolled asthma (LAVOLTA I and LAVOLTA II): replicate, phase 3, randomised, double-blind, placebo-controlled trials. Lancet Respir Med (2016) 4(10):781-96. doi:10.1016/ S2213-2600(16)30265-X

74. Wenzel S, Castro M, Corren J, Maspero J, Wang L, Zhang B, et al. Dupilumab efficacy and safety in adults with uncontrolled persistent asthma despite use of medium-to-high-dose inhaled corticosteroids plus a long-acting beta2 agonist: a randomised double-blind placebo-controlled pivotal phase 2b dose-ranging trial. Lancet (2016) 388(10039):31-44. doi:10.1016/ S0140-6736(16)30307-5

75. Johansson MW, Annis DS, Mosher DF. Alpha(M)beta(2) integrin-mediated adhesion and motility of IL-5-stimulated eosinophils on periostin. Am J Respir Cell Mol Biol (2013) 48(4):503-10. doi:10.1165/rcmb.2012-0150OC

76. Bochner BS, Klunk DA, Sterbinsky SA, Coffman RL, Schleimer RP. IL-13 selectively induces vascular cell adhesion molecule-1 expression in human endothelial cells. J Immunol (1995) 154(2):799-803.

77. Li L, Xia Y, Nguyen A, Lai YH, Feng L, Mosmann TR, et al. Effects of Th2 cytokines on chemokine expression in the lung: IL-13 potently induces eotaxin expression by airway epithelial cells. J Immunol (1999) 162(5):2477-87.

78. Takayama G, Arima K, Kanaji T, Toda S, Tanaka H, Shoji S, et al. Periostin: a novel component of subepithelial fibrosis of bronchial asthma downstream of IL-4 and IL-13 signals. J Allergy Clin Immunol (2006) 118(1):98-104. doi:10.1016/j.jaci.2006.02.046

79. Karelina T, Voronova V, Demin O, Colice G, Agoram BM. A mathematical modeling approach to understanding the effect of anti-interleukin therapy on eosinophils. CPT Pharmacometrics Syst Pharmacol (2016) 5(11):608-16. doi:10.1002/psp4.12129
80. Johansson MW, Khanna M, Bortnov V, Annis DS, Nguyen CL, Mosher DF. IL-5-stimulated eosinophils adherent to periostin undergo stereotypic morphological changes and ADAM8-dependent migration. Clin Exp Allergy (2017). doi:10.1111/cea.12934

81. Esnault S, Johansson MW, Kelly EA, Koenderman L, Mosher DF, Jarjour NN. IL-3 up-regulates and activates human eosinophil CD32 and alphaMbeta2 integrin causing degranulation. Clin Exp Allergy (2017) 47(4):488-98. doi: $10.1111 /$ cea. 12876

82. Woodruff PG, Boushey HA, Dolganov GM, Barker CS, Yang YH, Donnelly S, et al. Genome-wide profiling identifies epithelial cell genes associated with asthma and with treatment response to corticosteroids. Proc Natl Acad Sci US A (2007) 104(40):15858-63. doi:10.1073/pnas.0707413104

83. Jia G, Erickson RW, Choy DF, Mosesova S, Wu LC, Solberg OD, et al. Periostin is a systemic biomarker of eosinophilic airway inflammation in asthmatic patients. J Allergy Clin Immunol (2012) 130(3):647-54.e10. doi:10.1016/j.jaci.2012.06.025

84. Nagasaki T, Matsumoto H, Kanemitsu Y, Izuhara K, Tohda Y, Horiguchi T, et al. Using exhaled nitric oxide and serum periostin as a composite marker to identify severe/steroid-insensitive asthma. Am J Respir Crit Care Med (2014) 190(12):1449-52. doi:10.1164/rccm.201407-1290LE

85. Johansson MW, Evans MD, Crisafi GM, Holweg CT, Matthews JG, Jarjour NN. Serum periostin is associated with type 2 immunity in severe asthma. J Allergy Clin Immunol (2016) 137(6):1904-7.e2. doi:10.1016/j. jaci.2015.12.1346

86. Mosher DF, Johansson MW, Gillis ME, Annis DS. Periostin and TGFbeta-induced protein: two peas in a pod? Crit Rev Biochem Mol Biol (2015) 50(5):427-39. doi:10.3109/10409238.2015.1069791

87. Abdala Valencia H, Loffredo LF, Misharin AV, Berdnikovs S. Phenotypic plasticity and targeting of Siglec-F(high) CD11c(low) eosinophils to the airway in a murine model of asthma. Allergy (2016) 71(2):267-71. doi:10.1111/ all. 12776

88. Mesnil C, Raulier S, Paulissen G, Xiao X, Birrell MA, Pirottin D, et al. Lungresident eosinophils represent a distinct regulatory eosinophil subset. J Clin Invest (2016) 126(9):3279-95. doi:10.1172/JCI85664

89. Rothenberg ME. A hidden residential cell in the lung. J Clin Invest (2016) 126(9):3185-7. doi:10.1172/JCI89768

Conflict of Interest Statement: MJ received a fee for consulting from Guidepoint Global, a fee from Genentech for speaking, and funds for research from Hoffmann-La Roche; and is an advisory board member for Genentech.

Copyright (c) 2017 Johansson. This is an open-access article distributed under the terms of the Creative Commons Attribution License (CC BY). The use, distribution or reproduction in other forums is permitted, provided the original author(s) or licensor are credited and that the original publication in this journal is cited, in accordance with accepted academic practice. No use, distribution or reproduction is permitted which does not comply with these terms. 